\title{
Circulação de textos midiáticos entre alunos de escola pública básica
}

Juvenal Zanchetta Junior

Universidade Estadual de São Paulo

\begin{abstract}
Resumo
0 texto descreve características da leitura de temas midiáticos por alunos da escola pública básica do estado de São Paulo, delineadas a partir de observação sistemática da circulação de textos de imprensa no cotidiano escolar. Ao longo de dois anos letivos, em trabalho realizado com grupos de alunos do ensino fundamental e médio de duas escolas periféricas de município localizado no interior do estado, foram acompanhados os relatos dos estudantes acerca da apropriação feita por eles de informações midiáticas, obtidas em meios de comunicação diversos, com destaque para o jornal impresso. Durante o período pesquisado, entrevistas individuais e coletivas e textos produzidos pelos alunos foram utilizados como ponto de partida para a análise. Entre os aspectos destacados a partir do contato com os meios de comunicação, está o assentamento da informação de imprensa na escola, mas com repercussão fragmentada, não integrada ao cotidiano pedagógico e circunstancial na vida dos alunos. Os temas que recebem maior atenção circulam pela televisão, mediados pela família ou pelos pares, mas não pelo professor. Uma proposta de análise desses dados é seguida de sugestões concretas para o tratamento de suportes, textos e temas midiatizados na escola, considerando os recursos disponíveis e o contexto da escola tal como ela se mostra nos dias de hoje.
\end{abstract}

Palavras-chave

Leitura - Aluno - Texto - Mídia - Escola pública. 


\title{
The circulation of media texts among pupils in public basic education
}

Juvenal Zanchetta Junior

Universidade Estadual de São Paulo

\begin{abstract}
The text characterizes the reading of media-related materials by students of the public basic education system in the State of São Paulo, based on a systematic observation of the circulation of press texts within the school daily life. In a study carried out during two academic years with groups of students from fundamental and secondary education classes belonging to two different schools situated in the outskirts of a town in the interior of the state, the students' reports on their appropriation of media-based information obtained from a variety of sources were analyzed, with particular emphasis on written newspapers. During the period investigated individual and group interviews, as well as texts produced by the students, were taken as points of departure for the analysis. Among the aspects noted from the contact with communication media is the establishment of press information inside the school, albeit with fragmentary repercussions, not fully integrated into the pedagogical daily life, but somewhat circumstantial in the students' lives. The themes that receive more attention circulate through the television, mediated by family or peers, but not by teachers. A proposal for the analysis of these data is made, followed by concrete suggestions as to the treatment to be given to support material, texts and mediabased issues at school, taking into account the resources available and the school context such as it appears nowadays.
\end{abstract}

\section{Keywords}

Reading - Pupil - Text - Media - Public school. 
0 presente texto ${ }^{1}$ discute dados obtidos em pesquisa ${ }^{2}$ desenvolvida desde 2005 sobre a circulação de textos midiáticos entre professores e alunos de duas escolas públicas estaduais de São Paulo. Durante dois anos letivos, alunos matriculados no ensino fundamental e no início do ensino médio foram acompanhados com o objetivo de conhecer sua experiência, num primeiro momento, com as informações encontradas em suportes midiáticos diversos e, em seguida, apenas com jornais impressos. Com essas impressões, entre outras anotações ${ }^{3}$, buscam-se subsídios para a caracterização da circulação da informação no cenário escolar e também para propor alternativas ao trabalho com textos midiáticos na escola básica.

\section{Apoio conceitual}

Por informação noticiosa, trata-se não apenas de dados factuais, como os apresentados pelos meios de comunicação (MC), mas principalmente da versão construída individual e socialmente pelos agentes da comunidade escolar. Nota-se a informação inserida dentro de um contexto em sua capacidade de circulação e de fusão com outras informações. Há interesse na sua configuração original, mas observa-se com maior cuidado a maneira como ela é percebida. Busca-se a informação transformada em narrativa e, portanto, em conhecimento dos agentes escolares.

"Narrativa" implicaria o processo a partir do qual a informação é articulada numa história, representada simbolicamente, que situa o indivíduo no mundo que o cerca. Na escola, a narrativa escolar (ou as narrativas escolares) tem traços da moral cristã, um conjunto de princípios de cunho político (como a ideia de representação política) e valores ligados à civilidade (como o respeito ao próximo, o cultivo da tolerância), afora questões ligadas ao comportamento, que se juntam para compor uma ideia do mundo e uma proposta para o desenvolvimento e para o progresso (no caso da escola que chegou até os dias de hoje) ou uma proposta que preze a melhoria da vida e da convivência, a igualdade de condições entre as pessoas e o respeito ao meio ambiente, entre outros aspectos (em se tratando de ideias prestigiadas para a escola que se pretende daqui em diante).

Acompanha este trabalho a ideia de propiciar situações de leitura que possam ir além da mera recepção de informações atrelada ao consumo, à superficialidade, ao vazio intelectual supostamente provocado pela mídia. No caso da imprensa e, mais de perto, dos jornais de grande circulação, impressos ou digitais tomados como veículos representativos da ação midiática na sociedade contemporânea e observados mais de perto neste texto -, há que se observar o papel formador do jornalismo, cuja história apresenta diversos exemplos de compromisso com ideais democráticos. De acordo com Bucci (2004), o jornalismo propõe

[...] uma comunicação voltada para a informação, para a formação e educação do povo para a cidadania [...]. 0 jornalismo é concebido como função mediadora do espaço público, como veículo de argumentos mais ou menos racionais, isto é, que dialoguem entre si a partir dos pressupostos da razão. Assim é que seus valores éticos têm o seu ponto mais alto o compromisso com a verdade, vale dizer, com a busca da verdade, com a honestidade intelectual, com a objetividade [percebida menos como a descrição exata do objeto e mais pelo estabelecimento de padrões comuns e consensuais de entendimento entre os sujeitos produtores e leitores]. (p. 128)

Veículos de imprensa são empresas sensíveis às pressões políticas e econômicas, dispu-

1. Uma versão ampliada deste texto foi apresentada pelo autor em concurso de Livre-docência realizado na Faculdade de Ciências e Letras de Assis (UNESP), em 2008.

2. "Memória e circulação de gêneros textuais midiáticos na escola pública", pesquisa realizada desde 2005, com recursos do CNPq e do Núcleo de Ensino - UNESP. A etapa ora reportada teve a colaboração das alunas de graduação em Letras (UNESP-Assis) Flávia Santana e Helen Bernardes (2007), Gisele Gerevini, Silvia Mamede e Laiara Perin (2007/2008).

3. Outros estudos realizados, sobre temas correlatos, numa das escolas envolvidas, desde 2005. 
tam espaço no terreno da comunicação midiática (portanto, utilizam-se das regras de mercado) e revelam tendências ideológicas determinadas, elaborando suas versões e objetivando conferir a elas efeito de verdade. Essas razões, entre outras, levam às ideias de que tais veículos são manipuladores, "vendidos", superficiais, tendenciosos, poderosos demais, invasivos, desmedidos etc. Tais elementos fazem parte do conjunto de tensões que pautam as disputas na arena política pública.

Nesse território amplo e difuso, se um ou vários meios mostram-se supostamente enviesados num ou noutro aspecto, outros veículos e jornalistas tendem a outras posições. Isso não garante nenhum tipo de equilíbrio ou de regulação, mas é um fator que aponta para a diversidade de opiniões, mesmo em meio a um terreno monopolista como é aquele em que se situam os MC no Brasil, em que poucos grupos privados são decisivos para a configuração dos circuitos de informação midiática. De outro lado, ainda como contraponto à informação enviesada, há a possibilidade de reflexão, por parte dos indivíduos, a partir do acesso cada vez maior à informação, da comparação entre versões, da observação histórica, da socialização da informação.

Para esboçar o perfil da informação num determinado cenário escolar, as atividades insistiram na observação das relações diversas, de ordem econômica, cultural e ideológica, feitas pelos alunos a partir do estímulo de determinada notícia ou episódio cotidiano. Com isso, houve a intenção de esboçar as características das representações de mundo por parte dos estudantes, mas principalmente de observar as articulações feitas por eles para situar eventos vividos ou noticiados com os contextos nos que estavam inseridos (desde o contexto familiar até o contexto político mais amplo).

Buscou-se o esboço de uma gradação de complexidade de percepção dos estudantes em relação aos contextos que os cercam, observando as diferentes agendas que ocupam suas preocupações cotidianas (Barros Filho, 1999). Por agenda, compreende-se o conjunto de temas que se destaca entre as preocupações de um indivíduo ou de uma comunidade num dado momento. Inspira-se no conceito de agenda setting que, simplificadamente, implica tomar o noticiário dos $\mathrm{MC}$ menos como fruto da pesquisa sobre o que existe de extraordinário no mundo cotidiano e mais como acordo implícito entre os agentes e o público responsáveis pela circulação das informações. Essa gradação serviria apenas para efeito didático, com destaque pontual dos circuitos de informação do aluno, deixando ver as influências e as relações estabelecidas por ele quando da seleção e da apropriação das informações noticiosas, num determinado momento:

Plano interpessoal: esse plano ajuda de forma decisiva a compor as agendas temáticas individuais. Parentes, amigos, colegas de escola, com influência da mídia, da igreja e de outros grupos são decisivos para seleção, entendimento e usos da informação no cotidiano. Trata-se de um plano de experiências concretas, que auxilia a própria integração do indivíduo nos grupos sociais próximos;

Plano organizacional: a agenda temática é marcada pela ação de agentes representativos de organizações determinadas como a igreja, a mídia, a prefeitura, a escola e seus professores (por meio de assuntos motivadores de aulas ou de trabalhos voltados à formação dos indivíduos como nos projetos de prevenção quanto ao uso de drogas). A diferença entre este e o plano anterior está na relação entre o sujeito e os temas: a mediação aqui implica percepção acerca do papel das instituições. Esta agenda contém volume muito mais amplo de temas, pois são diversos os agentes e modos de informação que interagem com o leitor. Quando o aluno associa o buraco da rua em que mora às atribuições da prefeitura de sua cidade, ele transitaria por esse plano;

Plano sistêmico: temas e informações com os quais o leitor se depara fazem parte da agenda da sociedade ou de grupos maiores, em geral definidos pela opinião pública. Por opinião públi- 
ca, tem-se não a somatória de consensos sociais, mas a expressão de grupos considerados competentes para a organização dessa opinião, por sua vez transformada em objeto coerente para orientar posicionamentos dos grupos de poder. A "verdade" dessa opinião não está na sua qualidade, mas na quantidade de agentes que a compartilham. Teria havido alargamento na expressão da opinião pública: "à medida que aumentou o número dos agentes que lutavam para defini-la e agir sobre ela, a 'opinião pública' escapou progressivamente ao controle de alguns para se tornar resultante incerta de um conjunto de ações difíceis de controlar por um único agente, mesmo tratandose do próprio poder político" (Champagne, 1996, p. 71). São repercutidos pelos mesmos agentes dos planos anteriores, porém acabam associados pelo leitor a uma ideia mais abrangente de sociedade. 0 sujeito, nesse caso, consegue perceber a sociedade como a somatória de elementos (instituições, grupos, ações públicas e privadas, por exemplo) interativos. Ele percebe que os fatos sociais que 0 circundam estão ligados menos a eventos ou personagens determinadas e mais a fatores estruturais da sociedade.

Um determinado tema (como a violência) pode fazer parte dos três planos ou agendas e depende, para a sua compreensão, de variáveis diversas (e muitas vezes imponderáveis): a) a proximidade ou distância em relação ao fato noticiado; b) a experiência de vida pessoal e comunitária com os valores e costumes em que se acredita; c) o nível de letramento; d) o tempo e a intensidade da exposição e os enfoques de maior prestígio conferidos ao fato narrado; e) a disponibilidade do sujeito para a informação; entre outros aspectos. Tem-se, enfim, algo próximo da ideia de "horizonte de expectativas", no sentido proposto pela Estética da Recepção (Jauss, 1978; Bordini; Aguiar, 1988).

\section{Contexto}

As escolas em que a pesquisa se desenvolveu localizam-se na periferia do município de
Assis, interior do estado de São Paulo. Os grupos de alunos escolhidos são provenientes de famílias com renda máxima de cinco salários mínimos, com idades entre 11 e 15 anos e que não se destacavam pelo mau comportamento, pelo comportamento excessivamente dócil ou pelo desempenho escolar ótimo ou ainda abaixo da média. Esse conjunto de opções tende a conferir alguma representatividade ao contexto pesquisado.

Em 2007, foram compostos três grupos (um por turma, com média de dez integrantes, em apenas uma das escolas), com alunos interessados em participar da experiência, matriculados em turmas de $6^{\text {a }}$ e $8^{\text {a }}$ séries do ensino fundamental e $1^{\circ}$ ano do ensino médio. Houve encontros semanais, com cerca de 30 minutos, entre alunos e pesquisadores, no ambiente escolar, mas fora da sala de aula. Em 2008, optou-se por trabalhar com três turmas de alunos de cada escola, durante as aulas de português (uma turma de $8^{\text {a }}$ série e outras do $1^{\circ}$ ano do ensino médio). No segundo semestre de 2008, trabalhou-se com grupos de até dez alunos fora da sala de aula.

Em que pese a diversidade de estímulos, as atividades mais comuns desenvolvidas com orientação dos pesquisadores foram as seguintes: a) abordagem de temas cotidianos; b) leitura de exemplares de jornais diários impres$\left.\operatorname{sos}^{4} ; \mathrm{c}\right)$ leitura de jornal impresso em pequenos grupos; d) leitura individual de jornal impresso; e) redação de notícias para jornal escolar (impresso e, mais tarde, digital).

Em razão de obstáculos diversos ${ }^{5}$, que exigiram atividades adaptadas a cada situação (dificultando a equação dos percursos num todo linear), foram registrados os comportamentos e as práticas recorrentes em cada grupo. Reuniram-se apenas impressões concernentes ao con-

4. No início do segundo semestre de 2007 , foram disponibilizadas, com recursos do CNPq, assinaturas de jornais (dois exemplares do jornal Folha de S. Paulo e um exemplar do jornal Agora São Paulo). Em 2008, ampliouse para sete o número de assinaturas do jornal Folha de S. Paulo, mantendo a assinatura de um exemplar do jornal Agora São Paulo.

5. Como a resistência de vários alunos para a leitura de jornais impressos e digitais, por problemas de alfabetização ou mesmo de visão, ou ainda a dificuldade de preservação dos mesmos alunos dentro de um grupo, ao longo do tempo, em razão de faltas, indiferença dos estudantes, atividades concomitantes etc. 
tato dos pesquisadores com os alunos e ao contato havido entre os próprios alunos durante os encontros. Havia a pretensão de notá-los como grupo, em situações e posturas "escolares”, e também em situações menos tutoradas.

\section{Características da informação nas escolas}

Entre as características mais recorrentes observadas ao longo do período, destacam-se:

a) Um cenário de possibilidades de informação bastante grande, mas as ideias de excesso ou de acúmulo de informação midiática parecem menos consistentes, pois há sensivel indiferença em relação à diversidade de meios de "informação direta". Os canais privilegiados passam pela experiência das famílias e restringem-se, quase sempre, à televisão e à informação por terceiros. 0 perfil da informação de terceiros (a família, os vizinhos e as pessoas próximas), proveniente do rádio, dos jornais locais e das experiências locais, é atravessado pelas relações entre os indivíduos da própria comunidade - e menos pela relação direta com um determinado MC;

b) 0 hábito de assistência a telejornais e de busca por informações em jornais impressos ou na internet é fluido. A informação pelos telejornais, de maneira geral, é ocasional, fragmentada ou passada a eles pelos adultos. Em geral, a informação da televisão que impressiona os alunos diz respeito a crimes, acidentes e outros eventos de grande impacto;

c) Quando trataram do contexto próximo, os comentários voltaram-se à informação sobre os próprios alunos. Entre as notícias que circulavam nos corredores, estavam uma suposta gravidez precoce, a formação de novos casais nas turmas, as brigas entre meninos e meninas, os furtos de pequenos objetos, as insatisfações provocadas por procedimentos dos professores. Assuntos da ordem social maior (um tema político, econômico, tecnológico etc.) foram pouco destacados. As ações havidas nos grupos primários acabaram sendo uma medida para a compreensão do mundo, relativizandose a ideia de mudanças radicais de percepção e entendimento da história (em razão da velocidade de difusão e da fragmentação de conteúdos propostas pela mídia);

d) Com a inserção do jornal impresso (em 2007), vários alunos demonstraram resistência pela dificuldade que enfrentaram para ler os textos: acabaram por desinteressar-se e por impedir a leitura dos colegas. A leitura restringiu-se a fatos mais apelativos (como crimes e tragédias) e, sobretudo, àquelas informações acompanhadas por ilustração. Afirmaram, em diversas ocasiões, que não sabiam como ler o jornal (o suporte parecia a eles muito extenso). Embora os estudantes conhecessem os principais portais jornalísticos na internet, parte deles mostrou pouca mobilidade para ler nesses suportes;

e) Ao longo da pesquisa, o professor não se mostrou como vetor significativo de informação. Segundo os estudantes, raramente os professores usavam jornais ou revistas em sala de aula. Nas ocasiões em que os mestres teriam comentado acerca de temas de imprensa, estes se referiam a assuntos já amplamente divulgados. Nenhuma das matérias escolhidas pelos alunos para leitura no jornal teria sido estimulada por comentário feito por professores;

f) Na abordagem espontânea do jornal, os homens preferem o caderno de esportes e as tirinhas; as mulheres, a seção de horóscopo e as tirinhas. Familiarizados com a estrutura desses informativos, em 2008, os alunos passaram a observar o conjunto dos cadernos por mais tempo, antes de se deterem num ou noutro assunto. 0 fato de os jornais apreciados terem sido edições "do dia" não constituiu um estímulo expressivo. Os alunos contentaram-se em levar para casa edições de dias anteriores e mesmo a ler, em trabalho na 
escola, cadernos antigos. Interessava menos a novidade do que o assunto;

g) De maneira geral, acabaram por se fixar em matérias já vistas por eles em outras ocasiões, em especial na televisão, mas se dispuseram a ler textos mais longos e complexos. Houve entendimento suficiente (para a compreensão da narrativa linear) das matérias lidas, embora tenham sido percebidos problemas quanto a inferências internas mais complexas. 0 título, o subtítulo e a ilustração mostraram-se fundamentais para a impressão. A fusão de suportes ou de estratégias para a informação tornou-se fator que menos modificava do que dificultava a leitura primária;

h) 0 jornal foi percebido como um todo e não como um conjunto dividido em temáticas específicas. Os alunos folheavam todo o jornal e imaginavam que a leitura devesse ser feita de maneira linear, embora localizassem com facilidade seus assuntos prediletos. Em 2008, após as atividades na escola, os alunos levaram regularmente os jornais para casa. Em casa, eles pouco influenciaram a escolha de temas pelos familiares, mas sabiam quais matérias haviam sido escolhidas pelos parentes. 0 jornal mostrou-se como suporte novo e ainda sacralizado: em diversas oportunidades, o jornal foi levado para a casa e retornou, dias depois, trazido pelo aluno ainda inteiro e organizado;

i) Houve pouco conhecimento explícito sobre esferas mais abrangentes do que o próprio entorno do aluno. Por exemplo, num dos grupos, os estudantes não sabiam o que era uma faculdade ou o que era preciso fazer para ser um universitário. Os da primeira série do ensino médio sabiam a diferença entre uma instituição pública e uma instituição privada, mas não sabiam distinguir entre UNESP e UNIP, ambas situadas na cidade;

j) Em levantamento realizado noutra frente ${ }^{6}$, com alunos de $8^{a}$ série e $1^{\circ}$ ano do ensino médio, ao escrever para públicos distintos e cada vez mais distantes do seu cotidiano, os estudantes ficaram mais atentos às características de seus textos (evitando erros crassos e a exposição de pessoas específicas, por exemplo), mas continuaram a reportar vivências pessoais imediatas. Quando o público-alvo mostrou-se radicalmente distante (alunos de escolas portuguesas), a opção ocorreu por temas genéricos como o carnaval ou as belezas naturais do Brasil.

\section{Problematização}

A informação de imprensa circula na escola, porém a repercussão é fragmentada, pouco integrada no cotidiano pedagógico e circunstancial na vida dos grupos primários. Os temas midiáticos que recebem maior atenção circulam pela televisão e são acompanhados pela família ou pelos pares. Entre esses temas, sobressaem aqueles de maior apelo imediato. As notícias locais são mais apreciadas do que eventos distantes. Essa característica, aliás, ocorre mesmo com leitores de jornal: os noticiários locais e policiais apresentam-se como as seções mais lidas por homens e mulheres no país (Ribeiro, 2003). Por outro lado, o apreço pelas colunas de lazer coincide com as características apresentadas por leitores jovens de jornal ${ }^{7}$.

Temas como a violência e o crime, além do caráter apelativo e sentimental, destacam-se pela concretude, aproximando-se daquilo que Costa (2004) toma como contribuição imediata para a composição da identidade e da experiência de vida das pessoas. Noutro âmbito, isso pode ser visto como um efeito do processo de "objetalidade" e

6. Trata-se de frente realizada em uma das escolas que ora abordamos, com ênfase na observação do perfil dos textos noticiosos produzidos por alunos de uma mesma turma, durante dois anos letivos consecutivos, à medida que esses textos mudavam de suporte e de destinatário. Os estudantes escreveram, primeiramente, para seus próprios pares, para os alunos de outras escolas e para dirigentes de ensino (em meio impresso, sob a forma de um jornal). Em seguida, escreveram para alunos de escola localizada em outra cidade e, finalmente, para estudantes de uma escola pública portuguesa (em meio digital, sob a forma de um blog).

7. Pesquisa realizada pela empresa Ipsos/Marplan, em 2001, com indivíduos de todas as faixas de renda em todo o Brasil (Correia, 2002). 
de alteridade de que se revestem os elementos que ajudam na formação da identidade (Darriba; Castro, 1998). A materialidade conferida aos referidos temas auxiliaria a orientar, a prevenir e a preservar, em muitos casos, características de ordem moral.

0 quadro esboçado não apresenta contradições em relação às abordagens voltadas à ideia de "audiência ativa", cuja tese está na recepção da televisão (o veículo mais significativo entre os meios de massa) tomada como forma de resistência da cultura popular à cultura midiática proposta por setores econômicos dominantes ou, ainda, como modo de apropriação e interação com o mundo (Martín-Barbero, 1997; 2001; Livingstone, 2003; Silverstone, 1994; Canclini, 1999). Não se pode sustentar, portanto, a tese da manipulação pura e simples de conteúdos, que seriam introjetados pela audiência, numa situação agravada no caso de públicos jovens, tomados, por suposição, como mais vulneráveis.

Os alunos empregam os temas veiculados (em família e com amigos, por exemplo), para uso em sua própria vida. Embora os estudantes sejam sensiveis a temas como o cuidado com saúde, dinheiro, meio ambiente, causas sociais mais divulgadas, o perfil de recepção dessas informações expõe um interesse quase sempre voltado ao imediato, afirmativo, porém pouco negociado e mais fundado em convicções anteriores do que em argumentação disponível nos textos ou em consensos obtidos a partir de discussão entre pares.

Poucos assuntos de prestígio parecem assumir quase a condição de entidades e ofuscam quaisquer outros. Os alunos apresentam reduzido interesse em relação a contextos exteriores. A informação sobre o estado e o país, por exemplo, recebe atenção em situações extraordinárias (provocadoras de comoção ou repúdio) ou em momentos de grande visibilidade (a divulgação intensa por vários MC). Ainda assim, a entrada desses temas no cotidiano das famílias e dos alunos depende, em muito, do aval da televisão, que parece dar a "versão definitiva” acerca dos episódios. Por outro lado, essa ligação com o mundo independe do professor: o aluno não conta com a chancela daquele para a consolidação de sua argumentação com os pares. Essa constatação nos remete ao quadro dos costumes escolares.

Chervel (1990) e Julia (2001) propõem a escola como campo específico onde predominam costumes e práticas também específicos, centrados mais na própria rotina escolar do que nas proposições (e pressões) externas, de ordem política, científica, cultural etc. A escola seria um espaço em que se preconizam costumes ligados à disciplina cristã, cívica e intelectual, atravessados por uma ética desenhada a partir da experiência escolar e pelas circunstâncias (que implicam, também, interferências externas, posto que o campo escolar conta com frágil poder de barganha política). Essa provisoriedade para soluções internas explica, em parte, os movimentos de aproximação e de distanciamento havidos entre as práticas dos agentes escolares e as práticas juvenis. A “epistemologia da prática”, preconizada pela convencionalmente conhecida tendência dos "saberes docentes", aponta para a especificidade e vida própria da experiência docente - posta de maneira quase autônoma em relação à escola e aos alunos. Processos como o bullying sugerem, do outro lado, traços de autonomia no universo estudantil.

0 modo como é firmada a agenda temática dos alunos é um sintoma do equilíbrio cada vez mais tênue do campo escolar. Por um lado, está a tradição preceptoral do magistério, incentivada ainda pelas orientações legais para a educação. A legislação em vigor é genérica quando trata das finalidades da educação, mas o acento recai sobre a ideia de "formar para a cidadania". 0 artigo $2^{\circ}$ da atual LDB (Lei 9.394/96) afirma que a educação é "dever da família e do Estado, inspirada nos princípios de liberdade e nos ideais de solidariedade humana, tem por finalidade o pleno desenvolvimento do educando, seu preparo para o exercício da cidadania e sua qualificação para o trabalho". A LDB anterior (Lei 4.024/61) mostrava de forma mais destacada a proposta de construção do conhecimento científico: “o 
preparo do indivíduo e da sociedade para o domínio dos recursos científicos e tecnológicos que lhes permitam utilizar as possibilidades e vencer as dificuldades do meio" (artigo $1^{\circ}$ ). Tal concepção deixa em segundo plano o domínio do conhecimento científico e, embora encontre plena ressonância entre os professores ${ }^{8}$, delega a eles e seus critérios subjetivos a definição daquilo que deve ou não deve servir para a "formação cidadã". Isso ajuda a explicar o caráter fragmentado das relações entre professores, alunos e informações midiáticas.

A dificuldade de se imprimir caráter programático a essa formação torna a tarefa preceptoral ainda mais difícil, em razão, por exemplo, das disparidades econômicas e sociais do país; do fato de a escola não ser propriamente um espaço democrático (gerando, portanto, conflitos); e da pluralidade de agentes que interferem na vida do indivíduo. A escola mantém relações assimétricas entre seus sujeitos, partindo-se do princípio de que aquele que ensina está num patamar diferente daquele que aprende. Por outro lado, ao se tratar da escola como uma mera extensão social, no tocante à conscientização sobre a ideia de cidadania, corre-se o risco de "apagar as fronteiras da vida”, fazendo da escola um mundo tão adulto quanto o de fora (Brayner, 2001). Numa terceira via de argumentação, cidadania é um princípio legal, que varia de país para país. No Brasil, por lei, alguém só se torna cidadão aos 18 anos de idade. Boa parte dos estudantes, portanto, não é cidadã plena, pois os alunos são, em sua grande maioria, menores de idade. A onipresença, a espetacularidade e os expedientes de sedução tornam a mídia um agente se não formador, ao menos difusor de valores que parecem mais atraentes do que as propostas dos professores, que não contam mais com o prestígio institucional da escola seletiva de décadas atrás.

0 contexto dos professores não raramente repercute os mesmos temas de que se ocupam os alunos. Um sinal disso pode estar no perfil de publicações que circulam nas escolas públicas estaduais e municipais do Oeste Paulista ${ }^{9}$ : não há a assinatura de qualquer revista em 65\% dos estabelecimentos. Entre as que assinam, destacase a opção por publicações pedagógicas, seguindo tendência verificada em estudo mais amplo (Andrade et al., 2004). Revistas como Veja ou Época são raras. A circulação de jornais é pequena: $77 \%$ das escolas não assinam jornais impressos. Apenas 7\% das escolas mantêm assinaturas de jornais de âmbito nacional. Há porcentagem significativa de estabelecimentos (33\%) que recebem jornais locais. Estes, por sua vez, são pouco complexos e pouco investigativos. Enfim, a ênfase na temática local diz respeito não só aos alunos, mas também aos professores.

Por outro lado, prevalece, em termos de contato do aluno com o universo exterior, aquilo que esboçamos como plano interpessoal. Isso aumenta, mas também relativiza a influência dos meios de massa. Em que pese o fato de os temas elencados pelos estudantes fazerem parte da agenda midiática, o aluno tende a ser seletivo, pois apenas alguns temas veiculados, especialmente pela tevê, em determinados momentos, recebem a sua atenção. Os jovens compõem seu imaginário e seu entendimento de mundo a partir de referências próximas. Além de localizada ou evidenciada frequentemente em temas imediatos e apelativos, essa percepção exterior é limitada e pouco aberta a outros temas ou a outras abordagens. 0 resultado é um entendimento do mundo vitimizador, maniqueísta e, não raramente, preconceituoso.

Não é possível afirmar que os alunos estão confinados a um universo restrito e pouco permeável. Determinados assuntos, sobretudo aqueles mais próximos do cotidiano das famílias dos estudantes, são compreendidos em

8. $72 \%$ dos professores pensam em "formar cidadãos conscientes" outros $60 \%$ falam em "desenvolver criatividade e espírito crítico"; e "transmitir conhecimentos atualizados e relevantes' é prioridade apenas para $16 \%$ dos professores. (Andrade et al., 2004)

9. Dados constantes do relatório da primeira fase do projeto 'Literatura na escola: espaços e contextos: a realidade brasileira e portuguesa'. Coordenada por Renata Junqueira de Souza, a pesquisa observa as condições para a leitura em cerca de 100 escolas públicas municipais e estaduais da região Oeste do Estado de São Paulo. 
outros âmbitos. Existe a percepção crítica acerca do papel da polícia no bairro e na escola, bem como do papel dos governantes locais na vida da comunidade. Entretanto, essa visão assume em geral contorno paternalista: o prefeito cuida bem ou mal do bairro, a polícia ajuda ou atrapalha as ações realizadas na região ou na escola e assim por diante.

Nesse plano interpessoal, enfim, o professor parece ter um papel menos definido ou ao menos equivalente ao dos demais agentes para a definição e rumos dos temas midiáticos tratados na escola. Esse papel cabe a um conjunto de agentes: a televisão (com destaque), a família e os próprios pares. Esses últimos são determinantes em relação àquilo que, em termos de informação midiática, terá mais ou menos vida fora da sala de aula. Em suas falas, ao deixarem entrever, por exemplo, uma convivência embrutecida e monótona, os alunos constroem uma imagem coletiva que lhes parece conferir força de barganha: florescem processos de heteronomia, de cumplicidade entre pares, de busca pela visibilidade a partir do confronto com as instituições e seus agentes.

Esse quadro de divisão reflete a individualização das relações sociais contemporâneas, deixando transparecer fenômeno que Dubet e Martuccelli (1998) chamam de "desinstitucionalização dos processos de socialização":

Nem a escola, nem a família, nem as igrejas podem [mais] ser consideradas como instituições no sentido clássico do termo. Elas são cada vez mais quadros sociais nos quais os indivíduos constroem suas experiências e se formam ainda como sujeitos. Sem muita originalidade, nós observamos um processo de individualização crescente, uma projeção contínua do indivíduo sobre a cena. Esse indivíduo torna-se mais exposto e mais fortemente submisso a uma série de provas tendo a obrigação de ser livre e soberano. 0 encontro de uma estrutura social desarticulada e uma cultura do indivíduo provoca uma 'psicologização' crescente dos cons- trangimentos e conflitos sociais. É dessa maneira que é preciso interpretar as reivindicações identitárias que procedem menos das resistências do passado do que das maneiras de reconstruir as identidades e os modos de participação socializando as provas do indivíduo. (p. 17)

Há diversos argumentos que procuram diminuir a ideia do esgarçamento das relações sociais na escola. Entre eles, estão os estudos que abordam as representações sociais, tratando das diferenças entre a percepção individual do aluno e a percepção acerca da escola como um todo. Salles (1995), Franco e Novaes (2001), por exemplo, mostram que os alunos aparentam estar desinteressados pela escola e pessimistas quanto ao comportamento e futuro dos jovens, mas parecem confiantes em relação a si mesmos e em relação ao seu próprio futuro. Em levantamento mais recente, a justificativa dos alunos para estarem frequentando a escola (de $5^{\text {a }}$ a $8^{\text {a }}$ séries) tem como resposta predominante a busca por conhecimentos (formação teórica, cultura geral) e a ponte para a qualificação profissional (SEE/SP, 2005).

Essas respostas não necessariamente contrastam com a argumentação desenvolvida até aqui. Os objetivos de professores e de jovens são até certo ponto os mesmos, mas os caminhos e as expectativas sobre como chegar a isso podem divergir ${ }^{10}$. Não se trata de questionar a veracidade ou os exageros das informações dos alunos, mas sim de explorar um cenário em que a informação mostra-se fluida e tende a reforçar crenças preconcebidas, mais do que a estimular processos coletivos de construção de conhecimento.

\section{Alguma proposição}

A diversidade de situações propostas e as dificuldades operacionais para levar adiante pers-

10. Charlot (2005), por exemplo, sustenta o distanciamento entre a formação pretendida pelos alunos e aquela proposta pelos professores. 
pectiva mais acentuadamente etnográfica levaram à observação de comportamentos recorrentes entre os alunos, de algum modo observáveis também em outros levantamentos. Embora discutível, esse caminho se mostra ao menos indicial, para ajudar quanto ao rumo que ora se pretende: a busca de sugestões para melhorar o acesso e o trato da informação midiática na escola, tendo em vista os comportamentos mais comuns entre os alunos. A sugestão seguinte considera a suposta limitação e os obstáculos da agenda midiática (sobretudo a de imprensa) na escola, principalmente na escola pública.

0 trânsito restrito da informação midiática, compreendendo-se desde os textos noticiosos até mesmo os produtos midiáticos mais facilmente associados à juventude, está ligado à precária prática formal de interação da escola com a mídia. De um lado, não é possível responsabilizar a escola, pois não consta do seu estatuto essa atribuição, exceto como competência pessoal do professor. Tal competência, por sua vez, está abrigada na incerta perspectiva da "preparação para a cidadania”, algo que comporta toda e qualquer ação que se proponha "edificante".

Os instrumentos de Estado mais próximos da escola potencialmente capazes de ajudar nesse exercício estão pouco ajustados à dinâmica escolar ou dão pouca atenção à componente informativa voltada aos jovens. Canais de informação pedagógicos, como a TV Escola ou a TV Futura, oferecem recursos que precisam ser ajustados pelos agentes pedagógicos para uso em sala de aula: o conteúdo desses veículos é definido pelo agente emissor. 0 documentário, gênero de maior prestígio nesses veículos, torna-se rapidamente monótono diante de gerações cada vez mais acostumadas à ação imediata, ao espetáculo e ao non sense, encontrados em filmes e séries americanas, em programas de auditório voltados para o público jovem (na televisão).

Nos canais oficiais de informação na internet, a situação é precária. Note-se, por exemplo, a pesquisa acerca das atividades econômicas predominantes no estado de São Paulo realizada no sítio oficial do governo" ${ }^{11}$ a busca pela palavra "economia" leva o usuário a links de informação específica (os serviços prestados on line) ou à informação genérica, em geral de cunho publicitário. 0 sítio oficial apenas repete estratégia comum em sítios governamentais das mais diversas esferas. Esse tipo de pesquisa obriga a pesquisa em outros canais especializados (como o da Fundação SEADE). Estes, por seu turno, demandam apoio também especializado. Existe aí obstáculo suficiente para levar o jovem leitor à abordagem superficial e voltada ao consumo, como aquela encontrada na enciclopédia virtual Wikipedia: aparecem ali as principais atividades econômicas do estado de São Paulo com algum volume de dados. No caso do turismo, a estampa ilustrativa mostra o parque Hopi Hari ${ }^{12}$. Uma das principais conclusões do estudo coordenado por Rowlands (2008) é justamente a precarização dos processos de pesquisa por gerações de jovens que convivem desde cedo com a internet.

Para a ampliação de percursos de informação dentro da escola, com a consequente melhoria das condições para a diversificação da agenda individual e para a interação com outras agendas, a fim de que os estudantes sejam estimulados a observar contextos mais abrangentes de organização da História, sugerimos algumas iniciativas ancoradas em práticas escolares convencionais e num cenário de recursos disponíveis ou possíveis nos dias de hoje, para os organismos de Estado:

a) A criação de espaço, nos sítios oficiais, para a didatização das atividades de Estado, propondo-se a oportunidade de os estudantes terem acesso e poderem dialogar com as instâncias que produzem informações oficiais. Tal compromisso parece ser exequível em meio ao enorme volume de material de propaganda produzido hoje nesses mesmos sítios. Ao se fazer a busca por informações sobre a economia do estado de São Paulo, espera-se que

11. www.saopaulo.sp.gov.br

12. Disponível em: <http://pt.wikipedia.org/wiki/Turismo_em_S\%C3\% A30_Paulo>. Acesso em: 30 maio 2008. 
elas possam ser organizadas em linguagem apropriada para o público juvenil. Embora pareça simples, um exercício como esse é raro;

b) 0 fomento do trabalho dos professores de diversas áreas, pelos organismos ligados à área da Educação, com a disponibilização de canais de pesquisa e de leitura na internet, bem como a sugestão de trabalhos possíveis. Esse exercício pode ser feito a partir dos próprios recursos já disponíveis, sobretudo utilizando-se das oficinas pedagógicas (ou correlatos ligados aos organismos diretivos estaduais ou municipais) ou dos organismos públicos de amparo à educação básica. Uma iniciativa como essa demanda trabalho sistemático, algo que a prática de projetos pontuais, tão comum nas escolas (dada a portabilidade e visibilidade de projetos com tempo determinado e curto para desenvolvimento) não parece comportar;

c) A consolidação de espaços de leitura e debate de textos informativos na escola, fora da sala de aula. Pode ser mais produtivo o trabalho diário com pequenos grupos de alunos, fora da sala de aula, na biblioteca ou mesmo em outros locais. Existe a necessidade de se propor trabalhos com temáticas diversas, que deem aos alunos possibilidade de escolha. Exercícios como esse, feitos de maneira sistemática, enfrentando-se, com referências de diversos suportes, temas como a violência, pode levar a outros temas e a outros patamares de percepção sobre as preferências dos estudantes;

d) A produção de materiais de informação, sobre temas de interesse coletivo. Uma possibilidade é a produção de blogs ou mesmo de bancos de dados sobre a comunidade escolar. A razão dessa prática é menos a novidade em si e estímulo para a leitura e mais a consolidação de um espaço de preocupações coletivas e de busca por caminhos de pesquisa para acesso regular. 0 estabelecimento de uma rede de canais de informação provenientes das escolas pode ser monitorado pelos governos (municipal ou estadual), de modo a propor alternativas, conferir prêmios, compartilhar sugestões para novos projetos.

Essas sugestões são ilustrativas de ação possivel na escola paulista, mas exigem práticas sistematizadas. A proposição de novas rotinas no cotidiano escolar implica o recurso material, mas também o empenho e a negociação entre professores e alunos e a participação de instâncias diretivas externas. Exíguos, passionais e pouco compartilhados (entre professores e alunos), os temas midiáticos que circulam na escola nos dias de hoje ajudam, de um lado, a perpetuar um quadro de semi-informação primeiramente associado à ideia de consumo, quando não de auxílio à "regressão do espírito" (Le Breton, 2006). De outro, o modo difuso como essa informação se dá consolida a percepção acrítica, agravada hoje pela variedade de suportes digitais cada vez mais individualizados. Levantamento ${ }^{13}$ realizado em turmas de $5^{\text {a }}$ a $7^{\text {a }}$ séries de uma das escolas ora observadas, sobre os usos de meios eletrônicos e digitais no cotidiano, mostrou que: a) assistir à TV é a principal atividade de lazer para todas as turmas; b) à medida que os estudantes avançam em termos de escolaridade, aumenta seu tempo gasto com a TV (35\% dos alunos da 5 a série ficam mais de três horas diante da TV, mas na $6^{\mathrm{a}}$ e 7a, esses percentuais sobem para 50\% e 60\%, respectivamente); c) entre os programas favoritos, na $5^{\text {a }}$ prevalecem desenhos animados, mas nas séries seguintes, o gosto volta-se para novelas e seriados de TV: há clara mistura dos perfis infantil, adolescente e adulto na programação prestigiada. Embora não sejam os únicos responsáveis, tais fatores contribuem para a diminuição abrupta das visitas à biblioteca da escola: enquanto os alunos da 5 a série emprestam pelo menos 10 livros ou revistas por ano, segundo os registros disponíveis no acervo, os estudantes da $6^{\mathrm{a}} \mathrm{e}$ da $7^{\mathrm{a}}$ retiram, em média, apenas três e uma publicação, por ano, respectivamente.

13. Realizado no final de 2008 , com quatro turmas de $5^{\mathrm{a}}, 6^{\mathrm{a}}$ e $7^{\mathrm{a}}$ séries (cerca de 110 alunos), sobre preferências em termos de lazer e de equipamentos eletrônicos e digitais. 0 levantamento também incluiu observação, na biblioteca da escola, quanto ao empréstimo de livros e revistas. 
Enfim, as sugestões anteriores não tratam de substituir o professor, estimulando a ideia de que a mídia é capaz de apresentar melhor explicação para o mundo, descredibilizando a experiência dos grupos primários e da escola. Não se espera também ampliação significativa do volume de assuntos para debate. Sabe-se que é limitado o conjunto de temas (ou agenda) passivel de análise concomitante (Barros Filho, 1999). A proposta ora apresentada, por outro lado, sugere o fomento da reflexão sobre a agenda temática que circula na escola, hoje em muito induzida pela mídia, buscando-se modos de adensar a experiência interpessoal, de professores e alunos, por meio da ação colaborativa, da observação organizada de hipertextos como o jornal impresso ou digital, da leitura e da revisão de opiniões. Considera-se a história preceptoral do professor, mas também a necessidade de se buscar outros modos de consolidar o papel docente.
0 tratamento isolado de matérias jornalísticas, em sala de aula, por exemplo, prática comum nos dias de hoje, inclusive a partir de iniciativas de governo, perpetua o quadro que vimos ao longo deste texto. 0 estímulo à problematização da informação na escola passa, inevitavelmente, pela ideia de consumo, inerente à informação midiática. Entretanto, a proposta reside em descobrir outros meios para a articulação da pesquisa midiática e para a interação entre os diversos agentes escolares.

A necessidade de novos modos de aproximação entre a escola e os MC de maior prestígio pode ser justificada de diversas maneiras, desde o ponto de vista histórico, até as razões mais pragmáticas ou generalistas. Desde que escape à tentação de ser tomada como projeto localizado para servir a uma ou a outra administração, tende a se constituir como iniciativa voltada à ideia de política educacional especificamente direcionada aos jovens.

\section{Referências bibliográficas}

ANDRADE, E. R. et al. 0 perfil dos professores brasileiros: pesquisa nacional - UNESCO. São Paulo: Moderna, 2004.

BARROS FILHO, C. Mundos possíveis e mundos agendados: um estudo do uso da mídia na sala de aula. In: BARZOTTO, V. H.; GHILARDI, M. I. (Orgs.). Mídia, educação e leitura. Campinas: ALB; Anhembi Morumbi, 1999. p. 32-45.

BORDINI, M. G.; AGUIAR, V. T. Literatura: a formação do leitor. Porto Alegre: Mercado Aberto, 1988.

BRAYNER, F. Da criança-cidadã ao fim da infância. Educação \& Sociedade, n. 76, p. 197-211, out. 2001.

BUCCI, E. Na TV, os cânones do jornalismo são anacrônicos. In: MIRANDA, D. S. (Org.). Ética e cultura. São Paulo: SESC; Perspectiva, 2004.

CANCLINI, N. G. Consumidores e cidadãos. Rio de Janeiro: Editora UFRJ, 1999.

CHAMPAGNE, P. Formar a opinião: o novo jogo político. Petrópolis: Vozes, 1996.

CHARLOT, B. Enquanto houver professores...: os universais da situação de ensino. In: de professores e globalização. Porto Alegre: Artmed, 2005. p. 75-87. Relação com o saber, formação

CHERVEL, A. História das disciplinas escolares: reflexões sobre um campo de pesquisa. Teoria \& Educação, n. 2, p. 177-229, 1990.

COSTA, J. F. 0 vestígio e a aura. Rio de Janeiro: Garamond, 2004.

DARRIBA, V.; CASTRO, L. R. Construções identitárias e a busca da felicidade na cultura de consumo. In: CASTRO, L. R. (Org.). Infância e adolescência na cultura do consumo. Rio de Janeiro: NAU, 1998. 
DUBET, F.; MARTUCCELLI, D. Dans quelle société vivons-nous? Paris: Seuil, 1998.

FERREIRA, A. P. Leitura de jornais em famílias de estudantes de escola pública de ensino fundamental. 2008. Dissertação (Mestrado em Educação)- Universidade Estadual de São Paulo, Marília, 2008.

FRANCO, M. L. P. B; NOVAES, G. T. F. Os jovens do ensino médio e suas representações sociais. Cadernos de Pesquisa, São Paulo, n. 112, p. 167-183, mar. 2001.

JAUSS, H. R. Pour une esthétique de la réception. Paris: Gallimard, 1978.

JULIA, D. A cultura escolar como objeto histórico. Revista Brasileira de História da Educação. n. 1, p. 9-42, jan/jun. 2001.

LE BRETON, D. Transviada juventude. Folha de S. Paulo, Caderno Mais!, p. 5, 30.07.2006.

LIVINGSTONE, S. Review of television, childhood and the home: a history of the making of the child television audience in Britain. Sociology, UK, v. 59, n. 2, p. 351-371, 2003.

MARTíN-BARBERO, J. Os exercícios do ver. São Paulo: Senac, 2001.

Dos meios às mediações: comunicação, cultura e hegemonia. Rio de Janeiro: UFRJ, 1997.

RIBEIRO, V. M. (Org.). Letramento no Brasil: reflexões a partir do INAF 2001. São Paulo: Global; Ação Educativa; Instituto Paulo Montenegro, 2003.

ROWLANDS, I. Information behavior of the researcher of the future. London: University College of London, 2008. Disponível em: <http://www.bl.uk/news/pdf/googlegen.pdf>. Acesso em: 15 fev. 2008.

SALLES, L. M. F. A representação social do adolescente e da adolescência: um estudo em escolas públicas. Cadernos de Pesquisa, São Paulo, n. 94, p. 25-33, ago. 1995.

SÃO PAULO (Estado). Secretaria de Estado da Educação. Sistema de Avaliação de Rendimento Escolar do Estado de São Paulo. São Paulo: SEE-SP, 2005.

SILVERSTONE, R. Televisión y vida cotidiana. Buenos Aires: Amorrutu, 1994.

Recebido em 06.04.09

Aprovado em 22.01.10

Juvenal Zanchetta Junior é professor do Departamento de Educação da UNESP - Assis e do programa de Pós-Graduação em Educação da UNESP - Marília. 